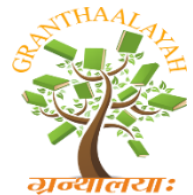

INTERNATIONAL JOURNAL OF RESEARCH GRANTHAALAYAH A knowledge Repository

Science

\title{
PREPARATION AND OPTICAL PROPERTIES CHARACTERIZATION OF P3OT - PMMA POLYMER BLEND FILMS
}

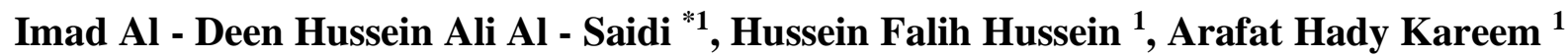 \\ ${ }^{1}$ Department of Physics, College of Education for Pure Sciences, University of Basrah, Basrah, \\ Iraq
}

\begin{abstract}
The optical properties of the Poly (3 - octylthiophene) (P3OT) - Poly (methyl methacrylate) (PMMA) polymer blend films at different percentage weight ratios of P3OT polymer were prepared using casting method. The optical absorbance and transmittance spectra of these films were measured in the wavelength range $300-1100 \mathrm{~nm}$ for different weight ratios of P3OT polymer using UV-Visible double - beam spectrophotometer. These optical spectra were used to determine the optical properties of the prepared polymer films. The main optical parameters of the polymer blend film, such as, reflectance $(\mathrm{R})$, absorption coefficient $(\alpha)$, extinction coefficient $(\mathrm{k})$, refractive index $(\mathrm{n})$, real and imaginary parts of dielectric constant $\left(\varepsilon_{\mathrm{r}}\right.$ and $\left.\varepsilon_{\mathrm{i}}\right)$, and optical energy band gap $\left(E_{g}\right)$, were determined. The effect of the weight ratio of P3OT polymer on these parameters was studied. The results showed that the prepared P3OT - PMMA polymer blend films exhibited suitable optical properties for the applications of solar cells, optical sensors, and photonic devices.
\end{abstract}

Keywords: Optical Properties; PMMA - P3OT Polymer Blend Films; Optical Parameters; Optical Energy Band Gap.

Cite This Article: Imad Al - Deen Hussein Ali Al - Saidi, Hussein Falih Hussein, and Arafat Hady Kareem. (2019). "PREPARATION AND OPTICAL PROPERTIES CHARACTERIZATION OF P3OT - PMMA POLYMER BLEND FILMS." International Journal of Research - Granthaalayah, 7(10), 238-246. https://doi.org/10.29121/granthaalayah.v7.i10.2019.392.

\section{Introduction}

Polymer materials have been received much attention from the researchers in the field of linear and nonlinear optics and the investigation of the optical and electrical properties of these materials is significantly grown due to their unique optical and electrical properties. These properties make these materials enable the development of several applications in optical photonic, and optoelectronic devices such as, optical sensors, solar cells, optical limiters, organic light emitting diodes (OLED's) [1 - 8]. Among various nonlinear materials, polymers have attracted much attention due to their practical applications. Poly (methyl methacrylate) (PMMA) and poly (3 octylthiophene) (P3OT) polymers have received great interest due to their diverse advantages [9, 10]; ease of fabrication and display optical, thermal, and chemical stabilities under environmental 
conditions. These polymers exhibit large absorption over the range of the visible region of the electromagnetic spectrum. In order to make these materials suitable for the device applications, the optical and electrical properties of these materials must be modified and develop. This is can be done effectively by mixing two or more polymers [9 - 12] or by doping the polymer with a suitable organic dye $[6-8,14]$. In the present study, P3OT - PMMA polymer blend films were prepared by the addition of different weight ratios of P3OT polymer to PMMA polymer. It was found that the optical and electrical properties of these polymer blend films were considerably affected by the change of the weight ratio of P3OT - PMMA polymer.

The optical characterizations of polymer blend films are important to obtain knowledge regarding their optical properties and the effect of changing the weight ratio of the P3OT on the features of the main optical parameters such as; absorption coefficient, extinction coefficient, refractive index, the real and imaginary parts of dielectric constant, and energy band gap, which are very important for various optical applications.

In this paper, we report the fabrication of P3OT - PMMA polymer blend films using the casting method. The optical properties of these polymer films were characterized and the main optical parameters were determined.

\section{Material and Experimental Details}

Poly (3 - octylthiophene) (P3OT) and Poly (methyl methacrylate) (PMMA) polymers were chosen for the present study. These materials were supplied by Sigma-Aldrich. The molecular formula of the P3OT polymer is $\left(\mathrm{C}_{12} \mathrm{H}_{18} \mathrm{~S}\right)_{\mathrm{n}}$ and its molecular weight is $70000 \mathrm{~g} / \mathrm{mole}$, while the molecular formula of the PMMA polymer is $\left(\mathrm{C}_{5} \mathrm{O}_{2} \mathrm{H}_{8}\right)_{\mathrm{n}}$ and its molecular weight is $84000 \mathrm{~g} / \mathrm{mole}$. The chemical structures of P3OT and PMMA polymers are shown in Fig. 1 (a) and (b), respectively. The P3OT - PMMA polymer blend was prepared using the well - known casting method. The preparation of the P3OT - PMMA polymer blend films were prepared as follows: First 6 gm of PMMA polymer was dissolved in $10 \mathrm{ml}$ of Chloroform. The solution was then stirred using a magnetic stirrer for few hours until the polymer completely dissolved. Then different percentage weight ratios of $\mathrm{P} 3 O T(0.013 \%, 0.018 \%, 21 \%, 0.025 \%$, and $0.030 \%)$ were added to the PMMA solution. Five solutions with different percentage weight ratios were obtained. These solutions were stirred separately using the magnetic stirrer until the two polymers mixed together and homogeneous solutions were formed. The final obtained solutions with different weight ratios of P3OT polymer were cast on thin glass slides and then kept to dry gradually and solid films formed. The average thickness of these films was around $900 \mathrm{~nm}$. The prepared film samples were examined and found they are uniform, stable, and show good optical quality.

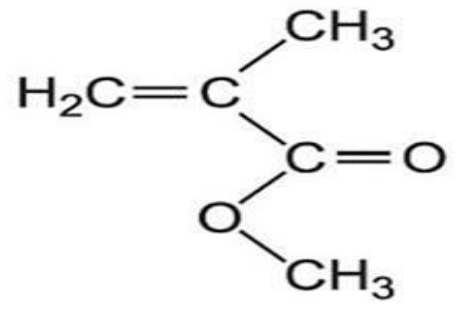

(a)

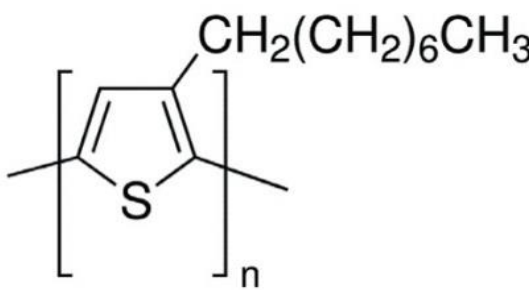

(b)

Figure 1: Chemical structures of PMMA polymer (a) and P3OT polymer (b) 


\section{Results and Discussion}

The absorbance (A) and the transmittance (T) of the P3OT - PMMA polymer bend films at different weight ratios were recorded over the wavelength range $300 \mathrm{~nm}-900 \mathrm{~nm}$ using UV-Vis double - beam spectrophotometer. The spectra of the absorbance and the transmittance are shown in Figs. 2 and 3, respectively. It is clearly seen in Fig. 2 that all the maximum absorption peaks are located around the wavelength $700 \mathrm{~nm}$. The lowest peak value of the absorbance (A) is $7 \%$ for the sample with the weight ratio of $0.013 \%$ of the P3OT polymer in the P3OT - PMMA polymer blend film. This value is considerably increased as the weight ratio of P3OT polymer increases and the highest value of $\mathrm{A}$ is $27 \%$ for the sample with the weight ratio $30 \%$ of the P3OT. The lowest transmittance value for the P3OT - PMMA polymer blend film is $65 \%$ for the sample with the weight ratio $30 \%$ of the P3OT polymer, as seen in Fig. 3, and this value is increased as the weight ratio of the P3OT polymer decreased The highest value of $\mathrm{T}$ is $90 \%$ for the sample with the weight ratio $0.013 \%$ of the P3OT polymer, at the wavelength $700 \mathrm{~nm}$. It clearly seen those values of the absorbance (A) and the transmittance $(\mathrm{T})$ are depending on the weight ratio of the P3OT polymer. The value of A increased when the weight ratio of P3OT polymer increased, while the value of $\mathrm{T}$ decreased when the weight ratio increased.

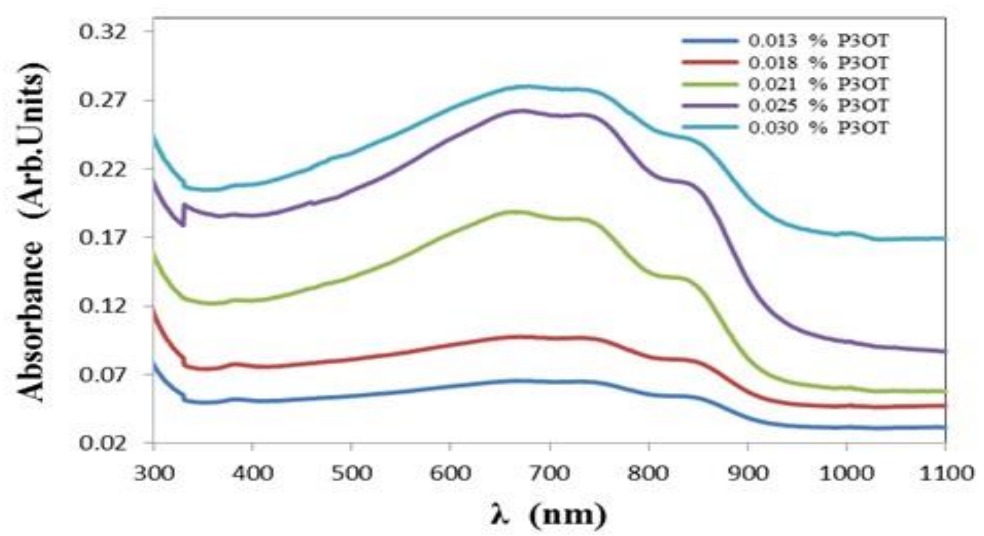

Figure 2: UV- Visible absorbance spectra of P3OT - PMMA polymer blend film at different weight ratios of $\mathrm{P} 3 \mathrm{OT}$.

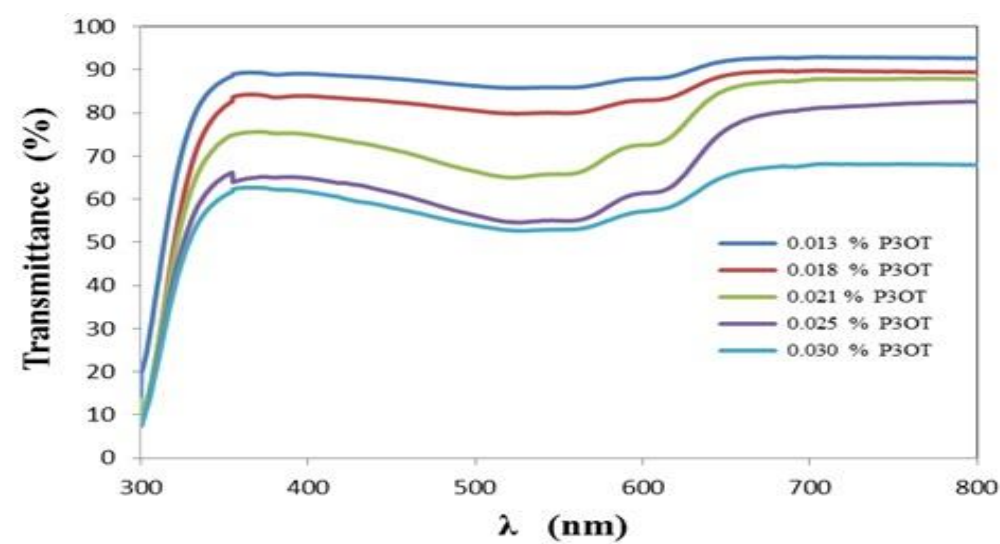

Figure 2: UV- Visible transmittance spectra of P3OT - PMMA polymer blend film for different P3OT polymer weight ratios. 
The value of the absorption coefficient $(\alpha)$ of the P3OT - PMMA polymer blend film samples was calculated for different percentage weight ratio of the P3OT polymer using the fallowing relation $[15,16]$ :

$$
\alpha=2.303 \frac{\mathrm{A}}{\mathrm{t}}
$$

where $\mathrm{A}$ is the absorbance and $\mathrm{t}$ is the thickness of the polymer film.

Fig. 4 is illustrated the relation between the linear absorption coefficient $(\alpha)$ and the incident photon energy ( $\mathrm{h} v$ ) for the P3OT - PMMA polymer blend film at different weight ratio of the P3OT polymer. It is clearly seen that the absorption coefficient $(\alpha)$ is increased with increasing the incident photon energy ( $h v$ ) and the weight ratio of the P3OT polymer. The highest value of the absorption coefficient $(\alpha)$ is approximately $7.25 \mathrm{~cm}^{-1}$ around the photon energy $\mathrm{h} v=2.25 \mathrm{eV}$ for the sample with the weight ratio $0.030 \%$ of P3OT polymer.

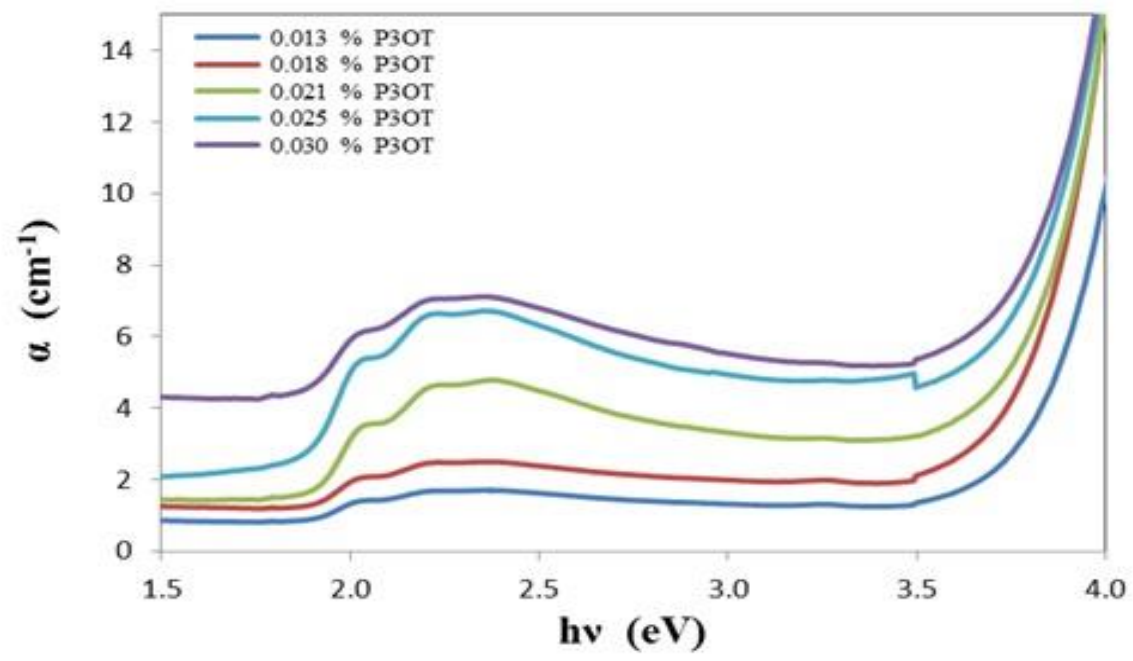

Figure 5: The absorption coefficient $(\alpha)$ of the P3OT- PMMA polymer blend film as a function of the incident photon energy $(\mathrm{h} v$ ) for different P3OT polymer weight ratios.

The reflectance $(\mathrm{R})$ of the P3OT - PMMA polymer blend film samples at different weight ratio of the P3OT polymer was calculated using the fallowing relation $[17,18]$ :

$$
\mathrm{R}=1-\left(\mathrm{T} \mathrm{e}^{\alpha \mathrm{t}}\right)^{1 / 2}
$$

where $\mathrm{T}=\mathrm{I} / \mathrm{I}_{0}$ is the transmittance of the film sample.

The obtained values of $R$ were plotted as a function of the wavelength ( $\lambda$ ), as shown in Fig. 5. As seen in this figure, the peaks of the optical spectra are located around the wavelength $\lambda=545 \mathrm{~nm}$ and the highest value of reflectance $(\mathrm{R})$ of the polymer sample is $\approx 17.5 \%$ for the sample with the weight ratio $0.030 \%$ of $\mathrm{P} 3 \mathrm{OT}$ polymer. This value is reduced for the other samples, and the lowest value of $\mathrm{R}$ is $4.6 \%$ for the sample with the weight ratio $0.013 \%$ of P3OT. 


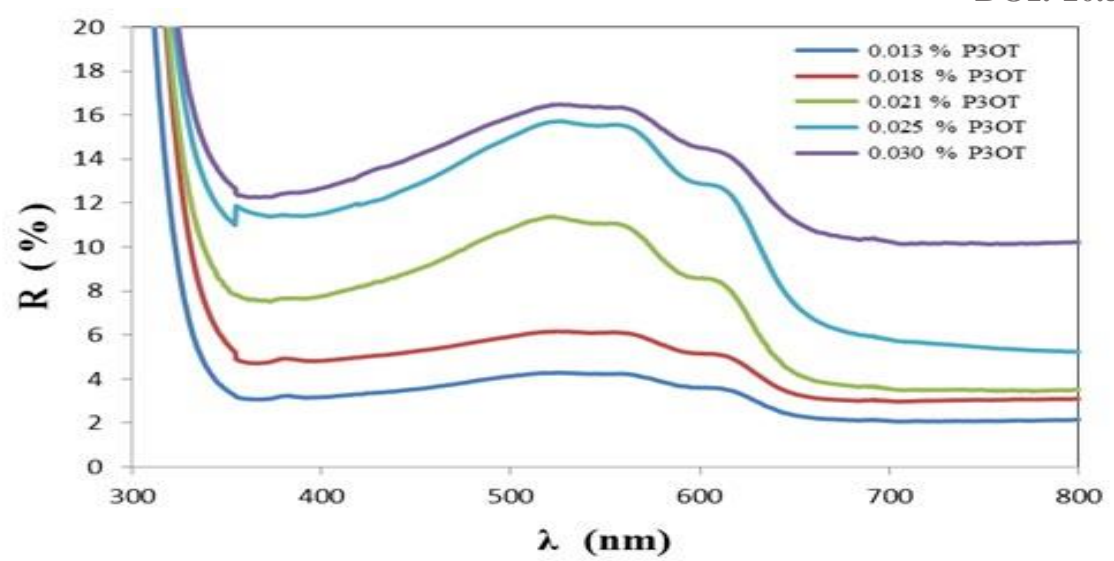

Figure 4: UV- Visible reflectance spectra of P3OT - PMMA polymer blend film for different $\mathrm{P} 3 \mathrm{OT}$ polymer weight ratios.

The extinction coefficient $(\mathrm{k})$ of the sample medium is given by the relation [17]:

$$
\mathrm{k}=\frac{\alpha \lambda}{4 \pi}
$$

where $\lambda$ is the wavelength of the incident light beam. This relation was used to calculate the value of $(\mathrm{k})$ for the P3OT - PMMA polymer blend film samples at different weight ratio of the P3OT polymer. Fig. 6 displays the relation between the extinction coefficient $(\mathrm{k})$ and the incident photon energy $(h v)$, for the polymer film samples at different weight ratio of the P3OT polymer.

It is noted that the value of $\mathrm{k}$ depends on the weight ratio of P3OT polymer and this value is appreciably changed as the weight ratio changed. The highest peak value of $\mathrm{k} \approx 3.2 \times 10^{-5}$ around the incident photon energy $\mathrm{h} v=2.2 \mathrm{eV}$ for the polymer film sample with the weight ratio 0.030 $\%$ of P3OT polymer. It is obviously seen that the curve of the extinction coefficient (k) exhibited behavior is similar to that of the absorption coefficient $(\alpha)$, this is due the relation between the extinction coefficient $(\mathrm{k})$ and the absorption coefficient $(\alpha)$.

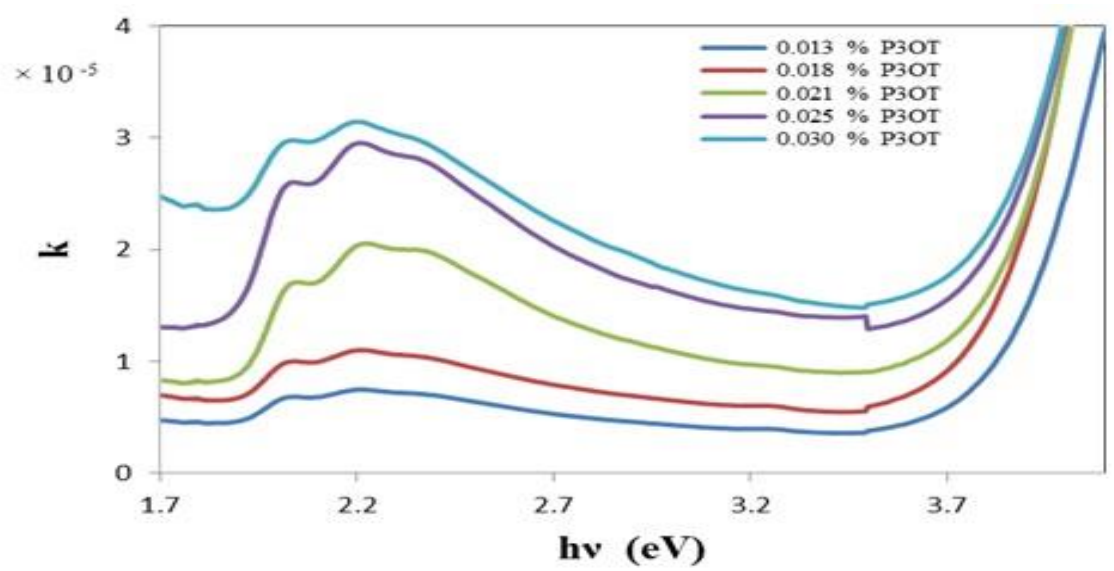

Figure 6: The extinction coefficient (k) of the P3OT- PMMA polymer blend film as a function of the incident photon energy $(\mathrm{h} v$ ) for different P3OT polymer weight ratios. 
The linear refractive index (n) of the samples of the P3OT - PMMA polymer blend film at different weight ratio of the P3OT polymer was calculated from the relationship between the extinction coefficient $(\mathrm{k})$ and the reflectance $(\mathrm{R})$ and is given by the following relation [19]:

$$
\mathrm{n}=\left[\frac{1+\mathrm{R}}{1-\mathrm{R}}\right]+\left[\frac{4 \mathrm{R}}{(1-\mathrm{R})^{2}}-\mathrm{k}^{2}\right]^{1 / 2}
$$

Fig. 7 displays the relation between the refractive index (n) and the incident photon energy (h $v$ ), for the polymer film samples at different weight ratio of the P3OT polymer. The value of the refractive index $(n)$ is varied within the range $1.5-2.2$ corresponding to the range $0.013 \%-$ $0.030 \%$ of the weight ratio of P3OT polymer The highest value of the refractive index (n) of the $\mathrm{P} 3 \mathrm{OT}$ - PMMA polymer blend film with the weight ratio of the P3OT is 2.2 at the incident photon energy $\mathrm{h} v \approx 2.3 \mathrm{eV}$.

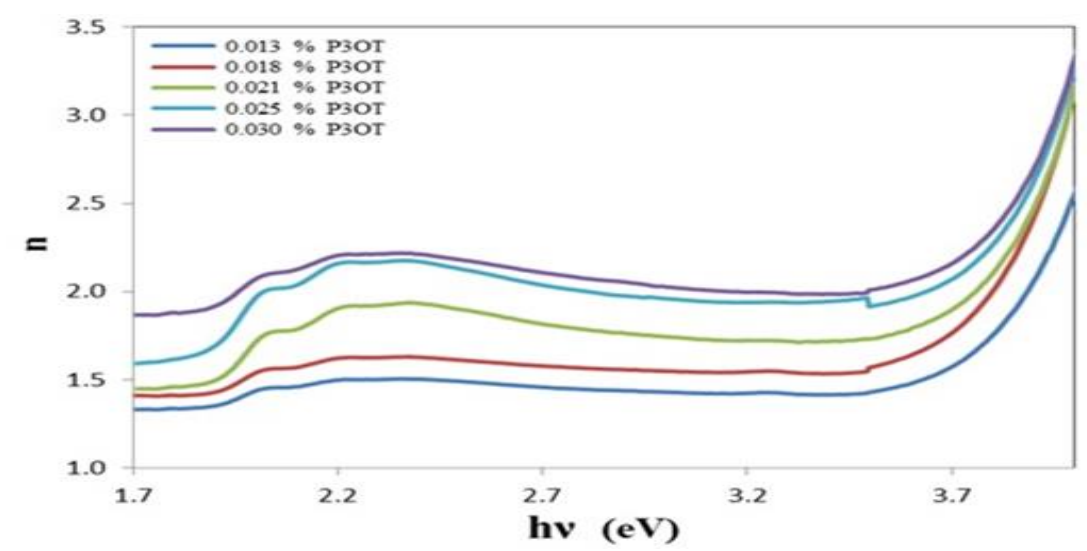

Figure 7: The refractive index (n) of the P3OT- PMMA polymer blend film as a function of the incident photon energy $(h v)$ for different P3OT polymer weight ratios.

The complex dielectric constant of the sample medium is defined by the following relation [17]:

$$
\varepsilon=\varepsilon_{\mathrm{r}}+\mathrm{i} \varepsilon_{\mathrm{i}}
$$

Where $\varepsilon_{\mathrm{r}}$ and $\varepsilon_{\mathrm{i}}$ are the real and imaginary parts of the dielectric constant $(\varepsilon)$, respectively, and they are given by the following relations:

$$
\varepsilon_{\mathrm{r}}=\mathrm{n}^{2}+\mathrm{k}^{2}
$$

and

$$
\varepsilon_{\mathrm{i}}=2 \mathrm{n} \mathrm{k}
$$

The values of the real $\left(\varepsilon_{\mathrm{r}}\right)$ and the imaginary $\left(\varepsilon_{\mathrm{i}}\right)$ parts of the dielectric constant $(\varepsilon)$ of the P3OT - PMMA polymer blend film samples at different weight ratios of P3OT were calculated using Eqs. (6) and (7), respectively. Figs. 8 and 9 illustrate the relation between $\varepsilon_{\mathrm{r}}, \varepsilon_{\mathrm{i}}$ and the photon energy $(h v)$ for the polymer blend film samples at different weight ratios of P3OT polymer. It is 
clearly seen that the change in the weight ratio of the P3OT polymer causes significant change in the values of $\varepsilon_{\mathrm{r}}$ and $\varepsilon_{\mathrm{i}}$. These values are increased with increasing the weight ratio of the P3OT polymer. The highest values of $\varepsilon_{\mathrm{r}}$ and $\varepsilon_{\mathrm{i}}$ for the polymer blend film samples at the weight ratios $0.030 \%$ of the P3OT polymer are 5.0 and $13.5 \times 10^{-5}$, at the incident photon energy $\mathrm{h} v \approx 2.4$ $\mathrm{eV}$, respectively.

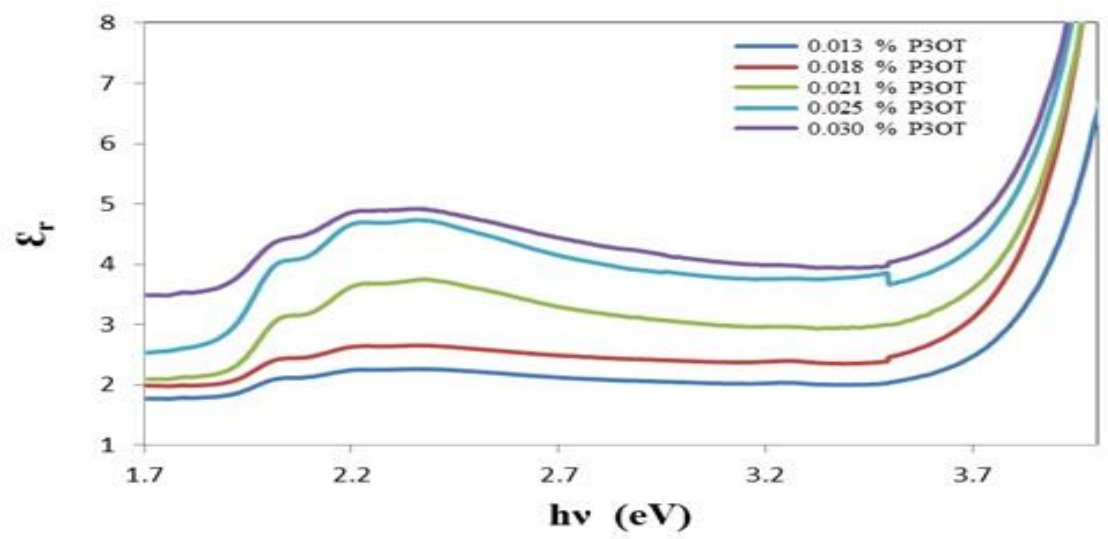

Figure 8: The real dielectric constant $\left(\varepsilon_{\mathrm{r}}\right)$ of the P3OT - PMMA polymer blend film as a function of the incident photon energy $(\mathrm{h} v)$ for different P3OT polymer weight ratios.

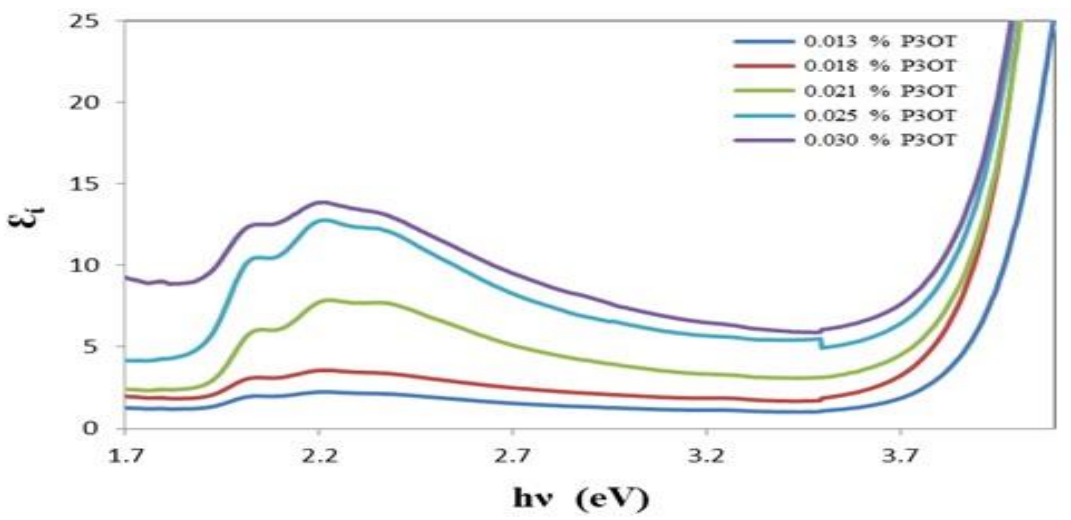

Figure 9: The imaginary dielectric constant $\left(\varepsilon_{\mathrm{i}}\right)$ of the P3OT - PMMA polymer blend film as a function of the incident photon energy $(\mathrm{h} v)$ for different P3OT polymer weight ratios.

The relation between the optical energy band gap $\left(\mathrm{E}_{\mathrm{g}}\right)$, the absorption coefficient $(\alpha)$, and the incident photon energy $(h v)$ is given by the Tauc's relation [20]:

$$
(\alpha h v)^{r}=B\left(h v-E_{g}\right)
$$

where $\mathrm{B}$ is a constant, $\mathrm{h}$ is the Planck's constant, $v$ is the frequency of the incident photons, and $\mathrm{r}$ is an index, its value depends on the electronic transition responsible for the absorption. $r=1 / 2$, $3 / 2,2$, or 3 for, direct allowed, direct forbidden, indirect forbidden, indirect allowed; transitions, respectively. In the present study, it is found that the mechanism of the measured absorption spectra of the samples is the indirect allowed transition, therefore, we have taken $r=1 / 2$ for determination the values of $E_{g}$; using Eq. (8). 
For evaluating the values of the optical energy band gap $\left(E_{g}\right)$ of the pure PMMA polymer film and the P3OT - PMMA polymer blend films at different weight ratios of P3OT polymer, we have plotted $(\alpha h v)^{1 / 2}$ versus $h v$, as shown in Fig. 10. The optical energy band gap $\left(\mathrm{E}_{\mathrm{g}}\right)$ can be obtained by extrapolating the linear portion of the plot to the $x$-axis, where $(\alpha h v)^{1 / 2}=0$. By using this procedure, the values of $\mathrm{E}_{\mathrm{g}}$ for the pure PMMA polymer film and blend polymer films at different weight ratios were determined. The obtained values are listed in the Table 1 . It can be seen from this table that the value of the pure PMMA polymer film is $4.73 \mathrm{eV}$ and it is significantly reduced for the polymer blend films. This decrease in the value of $\mathrm{E}_{\mathrm{g}}$ upon addition of weight ratio of P3OT polymer makes it possible to modify the properties of PMMA polymer.

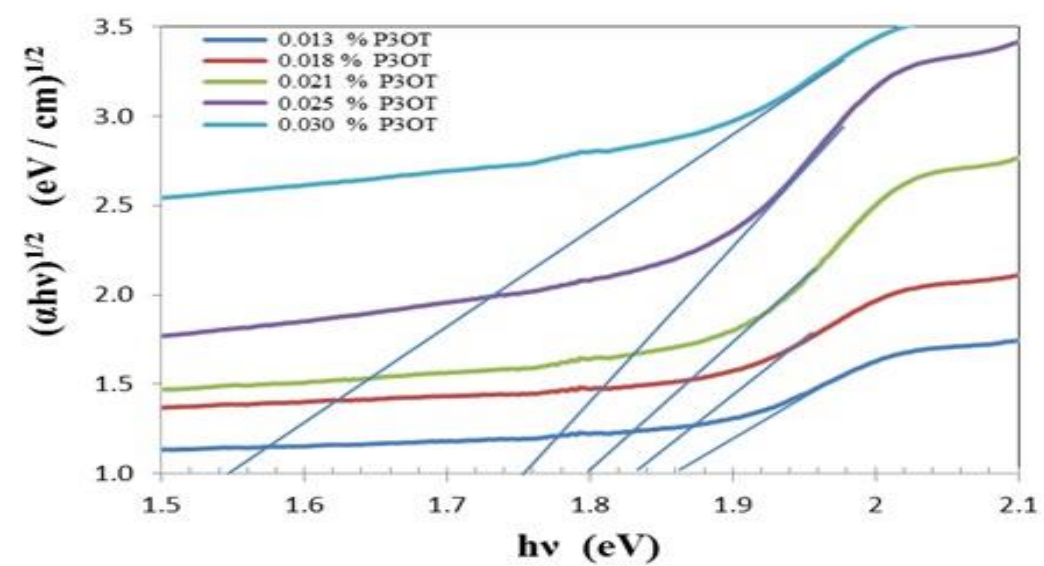

Figure 10: Plot of $(\alpha h v)^{1 / 2}$ versus the incident photon energy (h $\left.v\right)$ for the P3OT- PMMA polymer blend film for different P3OTpolymer weight ratios.

Table 1: The evaluated values of the optical energy band gap $\left(\mathrm{E}_{\mathrm{g}}\right)$ of the P3OT - PMMA polymer blend film for different P3OT polymer weight ratios.

\begin{tabular}{|c|c|}
\hline Sample & $\begin{array}{c}\text { Optical energy band gap (Eg) } \\
(\mathbf{e V})\end{array}$ \\
\hline Pure PMMA & 4.73 \\
\hline $0.013 \%$ P3OT & 1.86 \\
\hline $0.018 \%$ P3OT & 1.83 \\
\hline $0.021 \%$ P3OT & 1.80 \\
\hline $0.025 \%$ P3OT & 1.75 \\
\hline $0.030 \%$ P3OT & 1.55 \\
\hline
\end{tabular}

\section{Conclusion}

From the results of the present study, it can be concluded that the addition of P3OT polymer, with different weight ratios, to the PMMA polymer can significantly modify the optical properties of the pure PMMA polymer. The prepared polymer blend films obtained from the mixing of the P3OT polymer with the PMMA polymer, and then using the casting method, exhibited appreciable reduction in the optical energy band gap $\left(E_{g}\right)$ compared with the pure PMMA polymer film, where the $E_{\mathrm{g}}$ value of the pure PMMA polymer film $4.73 \mathrm{eV}$ reduced to $1.55 \mathrm{eV}$ for the polymer blend film sample with the weight ratio $0.03 \%$ of the P3OT polymer. The values of the essential optical parameters were determined in this study. It is found that the values of these parameters can be 
changed with changing the weight ratio of the P3OT polymer. The obtained results suggest the suitability of the prepared polymer blend films for the optical and photonic device applications.

\section{References}

[1] H. S. Nalwa, (Ed.), Handbook of Advanced Electronic and Photonic Materials and Devices (Academic Press, New York, 2001).

[2] O. Ostroverkhova, (Ed.), Handbook of Organic Materials for Optical and Optoelectronic Devices: Properties and Applications (Woodhead Publishing Ltd., UK, 2013).

[3] G. Harsanyi, Polymer Films in Sensor Applications: Technology, Materials, Devices and their Applications (Technomic Publishing Company Inc., Pennsylvania, USA, 1995).

[4] W. Hou, Y. Xiao, G. Han, and J. Yu Lin, "The Applications of Polymers in Solar Cells: A Review", Polymers, 11 (2019) 143.

[5] S.-L Yeh, C.-Y. Zhu, and S.-W. Kuo, "Transparent Heat - Resistant PMMA Copolymers for Pacing Light - Emitting Diode Materials", Polymers, 7 (2015) 1379 - 1388.

[6] Imad Al - Deen Hussein A. Al - Saidi and Saif Al - Deen Abdulkareem, "Study of Nonlinear Optical Properties and Optical Power Limiting of Leishman Dye Using Z-Scan Technique", Indian J. Phys., 89 (2015) 1199 - 1203.

[7] I. Al-D. H. Al-Saidi, and S. Al-D. Abdulkareem, "Nonlinear Optical Properties and Optical Power Limiting of Leishman Dye Using Z- Scan Technique”, J. Mater. Sci.: Mater Electron., 20 (2015) $2713-2718$.

[8] Imad Al - Deen Hussein A. Al - Saidi and Saif Al - Deen Abdulkareem, "Nonlinear Optical Properties and Optical Power Limiting Effect of Giemsa Dye Polymer Films", Opt. Laser Technol., 82 (2016) 150 - 156.

[9] U. Ali, K. Juhanni Bt, A. Karim, and N. A. Buang, "A Review of the Properties and Applications of Poly(methylmethacrylate) (PMMA)", J. Polymer Reviews, 55 (2015), 678 - 705.

[10] M. E. Nicho, D. Pena-Salgado, and P. Altuzar - Coello, "Morphological an Physicochemical Properties of Spin-Coated Poly (3-Octylthiophene) / Polystyrene Composite Thin Films", Thin Solid Film, 518 (2010) 1799 - 1803.

[11] L. H. Sperling, Introduction to Physical Polymer Science, (John Wiley and Sons, Inc., Hoboken, 2006).

[12] S. Rajendran, M. R. Prabhu and M. U. Rani, "Characterization of PVC / PEMA Based Polymer Blend Electrolytes", Int J Electrochem Sci, 3 (2008) 282290.

[13] H. Frey and H. R. Khan, (Eds.), Handbook of Thin Film Technology (Springer-Verlag, Berlin, Germany, 2015).

[14] C. Fleischmann, M. Lievenbrück, and H. Ritter, "Polymers and Dyes: Developments and Applications", Polymers, 7 (2015) 717 - 746.

[15] N. F. Mott and A. E. Davis, Electronic Process in Non - Crystalline Materials, 2 Edn, (University Press, Oxford, UK, 1979).

[16] D. E. Gray, American Institute of Physics Handbook, 3 Edn., (McGrow Hill Book Co., New York, USA, 1982).

[17] J. I. Pankove, Optical Processes in Semiconductors, (Prentice Hall, New York, USA, 1971).

[18] I. Eckertova, Physics of Thin Films, 2 Edn., (Plenum Press, New York, USA, 1986).

[19] T.S. Moss, Optical Properties of Semiconductors, (Academic Press, New York, USA, 1974).

[20] J. Tauc, Amorphous and Liquid Semiconductors, Vol. 159, (Plenum Press, New York, 1974).

*Corresponding author.

E-mail address: al_saidi_imad@ yahoo.com 